\title{
The economic impact of epilepsy: a systematic review
}

\author{
Katharina Allers ${ }^{1,2}$, Beverley M. Essue 1,3, Maree L. Hackett ${ }^{1}$, Janani Muhunthan ${ }^{1 *}$, Craig S. Anderson ${ }^{1,4}$, \\ Kristen Pickles ${ }^{1}$, Franziska Scheibe ${ }^{1,2}$ and Stephen Jan $^{1}$
}

\begin{abstract}
Background: In this review we aimed to determine the economic impact of epilepsy and factors associated with costs to individuals and health systems.

Methods: A narrative systematic review of incidence and case series studies with prospective consecutive patient recruitment and economic outcomes published before July 2014 were retrieved from Medline, Embase and Psyclnfo.

Results: Of 322 studies reviewed, 22 studies met the inclusion criteria and 14 were from high income country settings. The total costs associated with epilepsy varied significantly in relation to the duration and severity of the condition, response to treatment, and health care setting. Where assessed, 'out of pocket' costs and productivity losses were found to create substantial burden on households which may be offset by health insurance. However, populations covered ostensibly for the upfront costs of care can still bear a significant economic burden.

Conclusions: Epilepsy poses a substantial economic burden for health systems and individuals and their families. There is uncertainty over the degree to which private health insurance or social health insurance coverage provides adequate protection from the costs of epilepsy. Future research is required to examine the role of different models of care and insurance programs in protecting against economic hardship for this condition, particularly in low and middle income settings.
\end{abstract}

Keywords: Epilepsy, Direct costs, Indirect costs

\section{Background}

Epilepsy is one of the most common neurological conditions which occurs in about 5 to 8 cases per 1000 people per annum in developed countries [1,2]. Epilepsy affects people of all ages and although treatable, often requires lifelong medication and sometimes surgery to control seizures [3]. The high health care costs related to assessment and treatment, surgery and hospitalisation for seizures, as well as lost employment, income, and household work, are well recognised [4]. These costs vary according to the severity of the condition, response to treatment, length of time since diagnosis, and the perspective examined (e.g. health systems, societal or individuals and families). However, the economic impact of epilepsy has been poorly

\footnotetext{
* Correspondence: jmuhunthan@georgeinstitute.org.au

'The George Institute for Global Health, University of Sydney, Level 10, King George V Building, 83-117 Missenden Rd, PO Box M201, Camperdown, NSW 2050, Australia

Full list of author information is available at the end of the article
}

quantified and few studies have evaluated strategies to reduce it [5].

A previous review of the economic impact of epilepsy in high and low and middle income countries was undertaken in 2008 and does not incorporate more recent studies [6] Most other reviews were limited to high-income settings and show associations with the temporal stage and severity of the disease, seizure frequency, drug treatment or resistance, hospital admissions and level of disability [7-11]. However, heterogeneous methods are used and study samples are small, raising issues of generalisability in particular towards those in low resource settings where rates of epilepsy are high [1]. Furthermore, the focus of previous reviews has largely been limited to the expenditure from the perspective of the health sector, excluding individual and household impacts. The aim of our review was to provide an update of the evidence and to examine the costs of epilepsy from societal, health system and household perspectives.

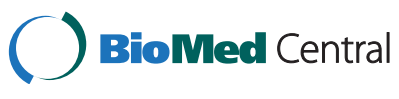

(c) 2015 Allers et al. Open Access This article is distributed under the terms of the Creative Commons Attribution 4.0 International License (http://creativecommons.org/licenses/by/4.0/), which permits unrestricted use, distribution, and reproduction in any medium, provided you give appropriate credit to the original author(s) and the source, provide a link to the Creative Commons license, and indicate if changes were made. The Creative Commons Public Domain Dedication waiver (http://creativecommons.org/publicdomain/zero/1.0/) applies to the data made available in this article, unless otherwise stated. 


\section{Methods}

Data were identified from published research articles and abstracts using a manual search in MEDLINE, Embase and PsycINFO databases, searched from inception to July 2014. We included incidence studies and case series with prospective consecutive patient recruitment within clearly defined geographical and time-limited boundaries. There were no restrictions on the basis of language, sample size, or duration of follow-up. Where articles were published in a language other than English, assistance was sought in translating the articles. Studies excluded were those limited to specific patient characteristics such as sex, where the recruitment strategy used convenience sampling with retrospective recruitment, were limited to unstructured assessment of psychosocial outcomes and focussed solely on clinical outcomes. If several articles reported outcomes from the same study population, data were taken from the first publication that referred to each follow-up period.

Two authors (KP, a public health researcher and Associate Professor $\mathrm{MH}$, Head, Mental Health and Chronic Disease Program, Neurological \& Mental Health Division) developed the search strategy using relevant terms that included common keywords for 'epilepsy' (e.g. epilepsy, epileptic, seizures, convulsions) combined with common keywords for 'costs' (e.g. economics, income, health care costs, expenses) (See Appendix for the search strategy). Epilepsy was defined as two or more recurrent unprovoked seizures. An epileptic seizure was diagnosed using the International League Against Epilepsy (ILAE) Commission on Epidemiology and Prognosis definition: "a transient occurrence of signs or symptoms due to abnormal excessive or synchronous neuronal activity in the brain." [12] We also accepted any criteria the study authors used for epilepsy, including idiopathic epilepsy and epileptic syndromes with seizures of localized onset; symptomatic epilepsy and epileptic syndromes with simple partial seizures; symptomatic epilepsy and epileptic syndromes with complex partial seizures; and generalized idiopathic epilepsy and epileptic syndromes. Provoked, unprovoked, cryptogenic, remote, status epilepticus, febrile, convulsive, absence were also included.

The outcomes included were the costs to the health system (drugs, hospitalisations, visits to family doctor, etc.), costs to individuals and households (out- of-pocket costs and patient co-payments associated with treatment), and indirect costs in terms of lost income and production. The latter could be measured either in monetary units or some other measure such as time off work.

$\mathrm{KP}, \mathrm{MH}$ and JM identified and reviewed papers for inclusion based on title and abstract in line with the inclusion criteria. The reference lists of all full text articles were reviewed to identify further articles of relevance that required retrieval of the full text. For all included studies (published full texts), a data extraction form was used to collect information on study design, setting, and outcome measures (Additional file 1) and data were extracted by one author (KA) and verified for accuracy (BE and SJ). The risk of bias in each study was assessed independently by the authors (KA, FS, MH and JM) using criteria based on a standard quality and risk-of-bias assessment [13].

Quantitative analysis was deemed inappropriate due to heterogeneity in the data, study designs and study settings. As this was a systematic review that did not involve data collection from participants, ethics approval was not required for this study.All information has been reported in accordance with PRISMA (Additional file 2) and MOOSE (Additional file 3) guidelines.

\section{Results}

Of 13588 papers retrieved, 322 studies were reviewed and 22 studies met the criteria for inclusion (see the PRISMA flowchart in Fig. 1). Table 1 summarises the characteristics of these studies where six were conducted from a health system perspective [14-19], seven were conducted from a societal perspective $[4,20-24,33]$, and nine from an individual perspective [25-32, 34]. Seven studies factored in out-of-pocket costs incurred by patients [17, 29-34] and three studies reported productivity losses due to reduced work capacity $[25,26,33]$. Seventeen studies reported direct costs related to epilepsy (Table 2) and 10 studies

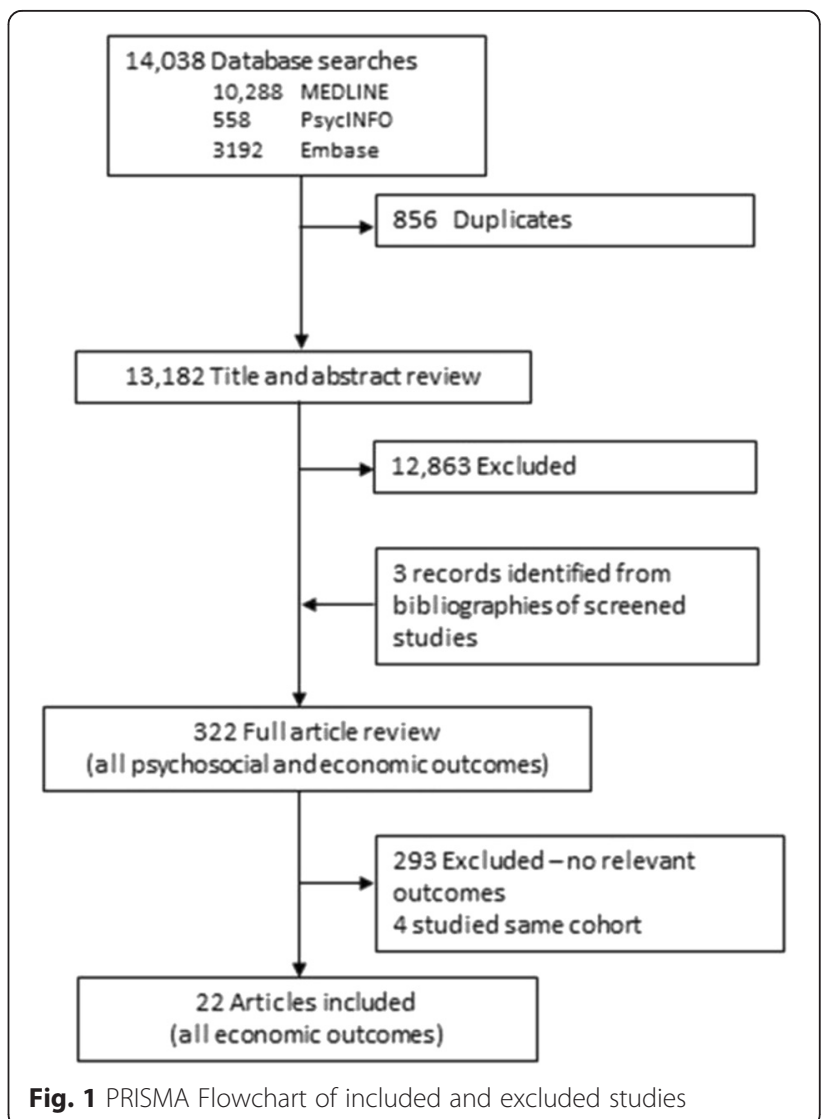


Table 1 Characteristics of studies included in review

\begin{tabular}{|c|c|c|c|c|c|c|}
\hline Study & Study design & $\mathrm{N}$ & Country Patient population & Study objective & Follow-up period & Economic outcomes measured \\
\hline Beghi et al. 2004 [14] & Cohort study & 631 & $\begin{array}{l}\text { Italy } 18 \text { years of age and olderNDE, } \\
\text { SR, OS, NDR, DR or SC*(HIC) }\end{array}$ & $\begin{array}{l}\text { To investigate the costs of epilepsy } \\
\text { in different prognostic categories }\end{array}$ & 12 months & - Direct costs \\
\hline Boon et al. 2002 [15] & Cohort study & 84 & $\begin{array}{l}\text { BelgiumAll agesPre-surgical } \\
\text { candidates who underwent a } \\
\text { complete pre-surgical evaluation } \\
\text { at Ghent University Hospital(HIC) }\end{array}$ & $\begin{array}{l}\text { To compare and economically } \\
\text { evaluate epilepsy-related direct } \\
\text { medical costs incurred by different } \\
\text { treatment modalities (conservatively, } \\
\text { surgically and vague nerve } \\
\text { stimulation- treated) and to determine. }\end{array}$ & $\begin{array}{l}\text { Mean follow-up } \\
\text { interval of } \\
26 \text { months }\end{array}$ & - Direct costs \\
\hline Cockerell 1994 [4] & Cohort study & 602 & $\begin{array}{l}\text { UKNewly diagnosed seizure } \\
\text { disorder (sample of the National } \\
\text { General Practice Study of Epilepsy } \\
\text { (NGPSE)(HIC) }\end{array}$ & $\begin{array}{l}\text { To assess the epilepsy related socio- } \\
\text { economic costs in a population so } \\
\text { that health care priorities can be set }\end{array}$ & $\begin{array}{l}\text { Mean follow-up } \\
\text { interval } 6.6 \text { years }\end{array}$ & - Direct costs \\
\hline Das et al. 2007 [25] & Cohort study & 1450 & $\begin{array}{l}\text { IndiaNo age indicatedNew } \\
\text { patients with epilepsy in the } \\
\text { Burdwan district(LMIC) }\end{array}$ & $\begin{array}{l}\text { To evaluate the rate of discontinuation } \\
\text { of epilepsy treatment and the related } \\
\text { socio-economic factors responsible for } \\
\text { discontinuation }\end{array}$ & 12 months & - Direct costs- Indirect costs- Income \\
\hline De Zelicourt et al. 2000 [20] & Cohort study & 1942 & $\begin{array}{l}\text { FranceMore than } 1 \text { month of age, } \\
\text { Newly diagnosed unprovoked } \\
\text { seizure(HIC) }\end{array}$ & $\begin{array}{l}\text { Estimation of the direct medical cost } \\
\text { for patients during the first two years } \\
\text { after diagnosis }\end{array}$ & 24 months & - Direct costs \\
\hline Farmer et al. 1992 [26] & $\begin{array}{l}\text { Quasi } \\
\text { randomized } \\
\text { trial }\end{array}$ & 215 & $\begin{array}{l}\text { EcuadorNo age indicatedEpilepsy } \\
\text { (identified in an epidemiological } \\
\text { survey)(UMI) }\end{array}$ & $\begin{array}{l}\text { To report the effects of epilepsy and } \\
\text { its treatment on the social functioning } \\
\text { of patients treated in Northern Ecuador }\end{array}$ & 12 months & - Employment status \\
\hline Guerrini et al. 2001 [16] & Cohort study & 189 & $\begin{array}{l}\text { ItalyChildren and } \\
\text { adolescentsFollowed up by child } \\
\text { neurologist (university department, } \\
\text { general hospital, outpatient } \\
\text { department)(HIC) }\end{array}$ & $\begin{array}{l}\text { To compare the direct costs of } \\
\text { epilepsy in a child neurology referral } \\
\text { population, stratified by disease, } \\
\text { duration, and severity, across three } \\
\text { health care settings. }\end{array}$ & 12 months & - Direct costs of epilepsy \\
\hline Halpern et al. 2011 [34] & Cohort study & 574 & USAAll agesEpilepsy(HIC) & $\begin{array}{l}\text { To assess whether people with } \\
\text { epilepsy who are uninsured and those } \\
\text { who have Medicaid coverage have } \\
\text { greater out-of-pocket costs }\end{array}$ & 6 years & - Out-of-pocket costs \\
\hline Helmstaedter et al. 2000 [33] & Cohort study & 161 & $\begin{array}{l}\text { GermanyAdultsSurgically or non- } \\
\text { surgically treated patients with } \\
\text { drug-resistant temporal lobe } \\
\text { epilepsy(HIC) }\end{array}$ & $\begin{array}{l}\text { To investigate the long-term effects of } \\
\text { surgical and non-surgical treatment of } \\
\text { drug-resistant temporal lobe epilepsy } \\
\text { according to socioeconomic } \\
\text { development }\end{array}$ & $\begin{array}{l}\text { Mean follow-up } \\
\text { interval } 58 \text { months }\end{array}$ & - Employment status \\
\hline Kotsopoulos et al. 2003 [17] & Cohort study & 116 & $\begin{array}{l}\text { NetherlandsAge not } \\
\text { indicatedEstablished epilepsy, } \\
\text { recruited from three patient } \\
\text { populations (general practices, } \\
\text { university hospital and epilepsy } \\
\text { centre)(HIC) }\end{array}$ & $\begin{array}{l}\text { (a) To gain insight into the direct and } \\
\text { indirect costs of epilepsy care, and(b) } \\
\text { To analyse the distribution of these } \\
\text { costs by type of services for each } \\
\text { patient group }\end{array}$ & $\begin{array}{l}3 \text { months } \\
\text { (and } 3 \text { months } \\
\text { retrospective) }\end{array}$ & $\begin{array}{l}\text { - Direct costs- Indirect costs- Out-of- } \\
\text { pocket costs }\end{array}$ \\
\hline
\end{tabular}


Table 1 Characteristics of studies included in review (Continued)

\begin{tabular}{|c|c|c|c|c|c|c|}
\hline Langfitt et al. 2007 [18] & Cohort study & 68 & $\begin{array}{l}\text { USA.Age not indicatedTemporal } \\
\text { lobe epilepsy patients(HIC) }\end{array}$ & $\begin{array}{l}\text { To determine whether health care } \\
\text { costs change when seizures are } \\
\text { controlled after surgery }\end{array}$ & $\begin{array}{l}2 \text { years (and } 2 \\
\text { years pre- } \\
\text { evaluation) }\end{array}$ & - Direct costs \\
\hline Lindsten et al. 2002 [21] & $\begin{array}{l}\text { Case-control } \\
\text { study }\end{array}$ & 63 & $\begin{array}{l}\text { Sweden } 17 \text { years of age or } \\
\text { olderNewly diagnosed } \\
\text { unprovoked seizure in } \\
\text { Vaesterbotten, northern } \\
\text { Sweden(HIC) }\end{array}$ & $\begin{array}{l}\text { To investigate the socioeconomic } \\
\text { prognosis after a newly diagnosed } \\
\text { unprovoked epileptic seizure }\end{array}$ & 10 years & $\begin{array}{l}\text { - Income- Source of income- Sickness } \\
\text { periods- Incapacity rate- Vocational status- } \\
\text { Education }\end{array}$ \\
\hline Pato Pato et al. $2011[22]$ & Cohort study & 171 & $\begin{array}{l}\text { SpainOver } 14 \text { years of } \\
\text { ageEpilepsy(HIC) }\end{array}$ & $\begin{array}{l}\text { To carry out an economic estimate of } \\
\text { the direct, indirect and intangible } \\
\text { costs of epilepsy }\end{array}$ & 6 months & - Direct costs- Indirect costs- Intangible costs \\
\hline Tetto et al. 2002 [19] & Cohort study & 525 & $\begin{array}{l}\text { ItalyAll agesNDE, SR, OS, NDR, DR } \\
\text { and SC from } 14 \text { epilepsy } \\
\text { centres(HIC) }\end{array}$ & $\begin{array}{l}\text { To compare the direct costs of } \\
\text { epilepsy in patients referred with } \\
\text { epilepsy of different severity and } \\
\text { duration }\end{array}$ & 12 months & - Direct costs \\
\hline Balabanov et al. 2007 [24] & Cohort study & 146 & $\begin{array}{l}\text { Bulgaria18 years of age and older } \\
\text { recruited from an epilepsy } \\
\text { centreEpilepsy(UMIC) }\end{array}$ & $\begin{array}{l}\text { To evaluate the effect of demographic } \\
\text { and clinical factors on the quality of } \\
\text { life and cost of treatment of epilepsy } \\
\text { patients on monotherapy with } \\
\text { carbamazepine and valproate }\end{array}$ & 12 months & - Direct costs- Indirect costs \\
\hline Lagunju et al. 2011 [32] & Cohort study & 215 & $\begin{array}{l}\text { NigeriaChildren over } 18 \text { months } \\
\text { recruited from apaediatric } \\
\text { neurology clinicEpilepsy(LMIC) }\end{array}$ & $\begin{array}{l}\text { To estimate the total cost of } \\
\text { childhood epilepsy and to provide } \\
\text { essential information on the economic } \\
\text { burden of childhood epilepsy in Nigeria }\end{array}$ & 12 months & $\begin{array}{l}\text { - Direct costs- Out-of-pocket costs- Indirect } \\
\text { costs }\end{array}$ \\
\hline Doumbia-Outtara et al. 2010 [31] & Cohort study & 70 & $\begin{array}{l}\text { Cote d'IvoireAdults recruited from } \\
\text { an inpatient unit within a hospital } \\
\text { department of neurology(LMIC) }\end{array}$ & $\begin{array}{l}\text { To evaluate the efficacy and tolerance } \\
\text { of anti-epileptic drugs and the } \\
\text { financial cost of care }\end{array}$ & $\mathrm{n} / \mathrm{a}$ & $\begin{array}{l}\text { - Direct costs- Out-of-pocket costs- Indirect } \\
\text { costs }\end{array}$ \\
\hline Dongmo et al. 2003 [30] & Cohort study & 125 & $\begin{array}{l}\text { CameroonAll ages recruited from } \\
\text { a medical centreEpilepsy(LMIC) }\end{array}$ & $\begin{array}{l}\text { To evaluate the difficulties faced in the } \\
\text { management of epileptic patients in } \\
\text { their natural environment }\end{array}$ & 12 months & - Direct costs- Out-of-pocket costs \\
\hline Haroon et al. 2012 [29] & Cohort study & 134 & $\begin{array}{l}\text { IndiaAll ages recruited from a } \\
\text { centre of neuroscience within a } \\
\text { national hospitalEpilepsy(LMIC) }\end{array}$ & $\begin{array}{l}\text { To evaluate the costs of active } \\
\text { epilepsy and study the pattern of drug } \\
\text { prescription and utilisation in epileptic } \\
\text { patients }\end{array}$ & 4 months & - Direct costs- Out-of-pocket costs \\
\hline Strzelcyck et al. 2013 [23] & Cohort study & 252 & $\begin{array}{l}\text { GermanyAll ages recruited from } \\
\text { anoutpatient clinic within a } \\
\text { university hospitalFocal } \\
\text { epilepsy(HIC) }\end{array}$ & $\begin{array}{l}\text { To estimate the direct and indirect } \\
\text { costs of epilepsy and evaluate trends } \\
\text { in the resource use of patients with } \\
\text { active epilepsy. }\end{array}$ & 12 months & -Direct costs-Indirect costs \\
\hline Lv et al. 2007 [28] & Cohort study & 533 & $\begin{array}{l}\text { ChinaParents of children with } \\
\text { epilepsy recruited from the } \\
\text { outpatient clinic of atertiary }\end{array}$ & $\begin{array}{l}\text { To assess the impact of childhood } \\
\text { epilepsy on parental quality of life } \\
\text { (QoL) and psychological health, and to }\end{array}$ & 12 months & - Direct costs- Income- Employment status \\
\hline
\end{tabular}


Table 1 Characteristics of studies included in review (Continued)

$$
\text { hospital epilepsy }
$$

investigate possible correlations

between parental QoL, background

between parental Qol, background

depression

Vlasov et al. $2010[27]$

Cohort study

RussiaEpilepsy(HIC)

To evaluate the clinical-economic

12 months

-Direct costs

effectiveness of anti-epileptic drug

(AED) therapy

Abbreviations: $D R$ drug-resistant seizures, NDE newly diagnosed epilepsy, NDR frequent non-drug-resistant seizures, OS occasional seizures, $S R$ seizure remission, $S C$ surgical

World Bank country classifications: HIC: high-income country; UMIC: upper-middle income country; LMIC: lower-middle-income country

(Accessible at: http://data.worldbank.org/about/country-and-lending-groups\#LLow_income) 
Table 2 Summary of findings - direct costs

\begin{tabular}{|c|c|}
\hline Study & Total direct costs \\
\hline Beghi et al. 2004 [14] & $\begin{array}{l}\text { Mean costs: €1302Subgroups: } \\
\text { NDE: €975; SR: €561OS: €830; } \\
\text { NDR: €1498; DR: €2568SC: €3619 }\end{array}$ \\
\hline Boon et al. 2002 [15] & $\begin{array}{l}\text { Conservatively treated } \\
\text { Before: } \$ 2,525 \\
\text { After: } \$ 2,421 \\
\text { Surgically treated } \\
\text { Before: } \$ 1,465 \\
\text { After: } \$ 1,186 \\
\text { Vagus Nerve Stimulation- } \\
\text { treated } \\
\text { Before: } \$ 4,826 \\
\text { After: } \$ 2,496\end{array}$ \\
\hline Cockerell et al. 1994 [4] & $\begin{array}{l}\text { Newly diagnosed seizures: } £ 611 \\
\text { (first year); } £ 169 \text { per patient per } \\
\text { annum (subsequent years) }\end{array}$ \\
\hline De Zelicourt et al. 2000 [20] & $\begin{array}{l}\text { First year: FF } 14 \text { 305Second year: } \\
\text { FF } 3766\end{array}$ \\
\hline Guerrini et al. 2001 [16] & $\begin{array}{l}\text { Mean annual cost: } € 1,767 \text { Subgroups: } \\
\text { Newly diagnosed epilepsy: } € 1,907 \\
\text { Seizure remission: } € 844 \text { Frequent non- } \\
\text { drug-resistant seizures: } € 1,112 \text { Drug- } \\
\text { resistant seizures: } € 3,268\end{array}$ \\
\hline
\end{tabular}

Halpern et al. 2011 [34]
Kotsopoulos et al. 2003 [17]

Langfitt et al. 2007 [17]

Pato Pato et al. 2011 [22]
GP: €625UH: €3,393EC: €4,292

Baseline vs Follow upPersisting seizure group: $\$ 2,224$ vs $\$ 2,982 \mathrm{No}$ surgery group: $\$ 1,838$ vs $\$ 2,567$ Surgery, seizure free group: $\$ 2,294$ vs $\$ 1,561$

$€ 2,110$ per year (€ 1055 for 6 months)

Out-of-pocket costs

$n / a$

1:Private; 2:Medicare age <65; 3:Medicare age $\geq 65$; 4:Medicaid, 5:Uninsured

Outpatient visits1) \$266; 2) \$56; 3) \$414; 4) $\$ 10$; 5) $\$ 397$

Hospital stays

1) $\$ 344 ; 2) \$ 5 ; 3) \$ 258 ; 4)$

\$2; 5) $\$ 1018$

Emergency department

1) $\$ 124 ; 2) \$ 16$; 3) $\$ 38$; 4) $\$ 33$; 5) $\$ 860$

Prescription medication

1) $\$ 809 ;$

2) $\$ 2192 ; 3) \$ 1446 ; 4)$

\$524; 5) \$1597

GP: €84UH: €1,767EC: €1,164

Costs of epilepsy patients vary significantly according to time course

of the disease and response to treatment. Hospital admissions and drugs are major sources of expenditure

As a result of offering epilepsy surgery and VNS to the patients, the costs of the most expensive patient group are reduced to the mean cost level of patients with refractory epilepsy. It takes some years to balance all direct costs incurred by epilepsy surgery and VNS by the savings after better seizure control and fewer hospital admissions.

Direct cost of $£ 611$ per patient per annum which decreased after eight years of follow-up to $£ 169$ per patient per annum.

Cost during first year sensitive to aetiologic categorisation of seizures and other clinical parameters. Cost during second year sensitive to frequency of seizure and treatment with AEDs.

The cost of epilepsy tends to vary significantly depending on the severity and duration of the disease. Hospital services and drugs are the major sources of costs. The setting of health care plays a significant role in the variation of the costs, even for patients in the same category of epilepsy.

Uninsured individuals had significantly fewer outpatient visits with neurologists, and greater antiepileptic drug costs than did those with private insurance. Individuals with Medicaid coverage had similar medical resource utilization but lower out-of-pocket costs compared with privately insured individuals.

Patients from GP appeared to have lower direct costs. The cost items anti-epileptic drugs, hospital services, unpaid care, and transportation accounted for the majority of the total direct costs.

Costs remain stable over 2 years post-evaluation in patients with temporal lobe epilepsy whose seizures persist, but patients who become seizure free after surgery use substantially less health care than before surgery. Further cost reductions in seizure-free patients can be expected as antiepileptic drugs are successfully eliminated.

See table 3 
Table 2 Summary of findings - direct costs (Continued)

\begin{tabular}{ll}
\hline Tetto et al. 2002 [19] & NDE: $€ 1002 ;$ SR: $€ 412 ;$ OS: $€ 558 ;$ \\
& NDR: $€ 1626 ;$ DR: $€ 2198 ;$ SC: $€ 3945$ \\
Balabanov et al. 2007 [24] & Patients on Carbamazepine \\
& Up to 2 adverse events (AEs): \\
& $€ 3392$ or more AEs: $€ 806$ \\
& Patients on Valproate \\
& monotherapy \\
& Up to 2 AEs: $€ 5812$ \\
& or more AEs: $€ 555$ \\
& n/a
\end{tabular}

Doumbia-Outtara et al. 2010 [31] n/a

Dongmo et al. 2003 [30]

Haroon et al. 2012 [29]

Strzelcyck et al. 2013 [23] $\mathrm{n} / \mathrm{a}$

$n / a$

Direct costs per patient (2003 cohort) Anticonvulsant drugs:

$€ 600$ Hospitalisation: €280Rehabilitatoin:

$€ 90$ Diagnostic work-up: €200utpatient care:

$€ 10$ Physical treatment: $€ 10 S p e c i a l$ equipment:

$€ 3$ Total: €1010

Direct costs per patient (2008 cohort)

Anticonvulsant drugs: €729

Hospitalisation: €350Rehabilitatoin: €112

Diagnostic work-up: €25Outpatient care:

$€ 13$ Physical treatment: $€ 13$ Special equipment:

$€ 4$ Total: $€ 1266$ $\mathrm{n} / \mathrm{a}$

Median direct costs for one year

AED costs: US\$288

n-patient care: US\$333

Investigation costs: US\$80

Out-patient costs: US\$32

Transportation: US\$20

Home care: US\$800

Mean direct costs of hospitalisation: 148715 FCFA

Examination: 74 FCFA

Accommodation: 58 FCFA

Anti-epileptic medicines: 17 FCFA

Average cost of treatment per

patient:31 CFA/day

Direct cost to epilepsy patients

prescribed 1-4 AEDs

1 AED: Rs5943

2 AEDs: Rs 8429

3 AEDs: Rs 10091

4 AEDs: Rs10683

$n / a$

t:

The direct costs of epilepsy vary significantly depending on the severity of the disease and the response to treatment. admissions and drugs are the most common items of expenditure.

Age, gender and type of seizure did not cause major differences in direct costs. In Carbamazepine patients costs were influenced by the incidence of AEs, time between seizures and percentage of seizure reduction. In Valproate patients costs were influenced by the time period between seizures.

Carers of children with epilepsy incur very high out-of-pocket expenses due to a lack of well-established national health insurance programme and social support services.

Phenobarbital was the most frequently used AED (40\%) and is the treatment of choice for patients. Financial accessibility to modern treatment of epilepsy is difficult as the cost of care is very high compared to the average salary. $22 \%$ of patients left the unit prematurely due to lack of financial means.

Phenobarbital was the most frequently used AED (75\%).

Compliance rate was $71 \%$ and the main reason for non-compliance was a lack of finances.

The direct cost to patients increased linearly with the addition of AEDs to patients' prescription. The majority of patients belonged to the lower middle income group. Some newer AEDs had a higher monthly cost (lamotrigine, levetiracetam and lacosamide) compared to older AEDs. Clobazam had the lowest cost of all newer AEDs.

Direct costs shifted during the 5-year period of evaluation of trends and resource. During this time hospital costs increased and a cost-neutral increase was observed in the prescription of 'newer' AEDs. 
Table 2 Summary of findings - direct costs (Continued)

Direct cost of seizures per patient (employed)

Primary generalized: 80 124,61

RUBSecondary generalized:84 006,43

RUBPartial focal: 77 099,28 RUBComplex focal:

7014,04 RUBPolymorphic/undifferentiated:84

461,56 RUBDirect cost of seizures per patients

(unemployed)Primary generalized: 67 754,36

RUBSecondary generalized:76 528,79

RUBPartial focal: 61 384,87 RUBComplex focal:

66 386,91 RUBPolymorphic/

undifferentiated 85 380,58 RUB

Although direct costs of treatment increased during the study period

the cost-benefit ratio significantly decreased by 2-3 times in all

types of seizures. The study found that rational treatment using

'new' AEDs would allow a reduction of the total cost of treatment.

Abbreviations: $A E D$ antiepileptic drugs, $D R$ drug-resistant seizures, $E C$ epilepsy
mission, SC surgical, $U H$ university hospital, na not colleted or not reported. 
Table 3 Summary of findings - indirect costs

\begin{tabular}{|c|c|c|c|c|}
\hline Study & Employment Status & Productivity loss & Income & Indirect costs summary \\
\hline $\begin{array}{l}\text { Das et al. } 2007 \\
\text { [25] }\end{array}$ & & & & $\begin{array}{l}\text { Most reported reason for discontinuation } \\
\text { was cost (90\%).Discontinued groupAverage } \\
\text { annual cost of treatment: Rs.5500 } \\
\text { ( } \$ 110) \text { Income: Rs. } 12,800 \text { ( } \$ 256) \text { Continued } \\
\text { groupAnnual cost of treatment: Rs.4500 } \\
\text { (\$90)Income: Rs. } 24,400 \text { ( } \$ 580)\end{array}$ \\
\hline $\begin{array}{l}\text { Farmer et al. } \\
1992[26]\end{array}$ & & & & $\begin{array}{l}\text { No difference in work days between people } \\
\text { with epilepsy and controls. Not enough } \\
\text { details provided in published paper to } \\
\text { provide quantitative comparison }\end{array}$ \\
\hline $\begin{array}{l}\text { Helmstaeder et } \\
\text { al. } 2000 \text { [33] }\end{array}$ & $\begin{array}{l}\text { (Baseline/Followup)N=161: } \\
\text { School (30/12) } \\
\text { Employed (82/87) } \\
\text { Unemployed (11/18) } \\
\text { Incapacitated (21/29) } \\
\text { House wife/husband (17/15) }\end{array}$ & & & $\begin{array}{l}\text { Socioeconomic outcomes was poorer in } \\
\text { nonsurgical than in surgical patients }\end{array}$ \\
\hline $\begin{array}{l}\text { Kotsopoulos et } \\
\text { al } 2003[17]\end{array}$ & $\begin{array}{l}\text { Temporally sick (n) } \\
\text { GP: 1; UH: 7; EC: } 4 \\
\text { Permanently sickGP: 0; UH: 0; EC: } 3 \\
\text { Work on therapeutic basisGP: 0; UH: 0; EC: } 2 \\
\text { UnemployedGP: 0; UH: 0; EC: } 2 \\
\text { RetiredGP: 3; UH: 11; EC: } 2 \\
\text { Early retirementGP: 0; UH: 2; EC: } 1 \\
\text { Part-time employmentGP: } 1 \text {; UH: 1; EC: } 0\end{array}$ & $\begin{array}{l}\text { Production days lost(days/month)GP: } \\
\text { OUH: OEC: 0.26Productivity loss } \\
\text { (hours/month)GP: OUH: 0.30EC: } 0.92\end{array}$ & & $\begin{array}{l}\text { People with epilepsy from the EC reported } \\
\text { the highest productivity losses and } \\
\text { unemployment rates }\end{array}$ \\
\hline $\begin{array}{l}\text { Lindsten et al. } \\
2002 \text { [21] }\end{array}$ & $\begin{array}{l}\text { (Control/Patients)1986-1990 (79/47) } \\
\text { Employed (76/41) } \\
\text { Unemployed } \\
\text { (3/3)Student (0/3) } \\
1991-1993(73 / 42) \\
\text { Employed (67/38) } \\
\text { Unemployed (4/1) } \\
\text { Student }(2 / 3) \\
\text { 1994-1996 (68/40) } \\
\text { Employed (60/34) } \\
\text { Unemployed } \\
\text { (5/3)Student (3/3) } \\
\text { 1997 (65/39) } \\
\text { Employed (63/33) } \\
\text { Unemployed (5/3) } \\
\text { Student (0/4) }\end{array}$ & & $\begin{array}{l}\text { (Control/Patients)1986-1990 (82/50) } \\
\text { From employment (75/33) } \\
\text { Sickness allowance }(0 / 5) \\
\text { Study grant/unemployment benefit (3/6) } \\
\text { Disability pension (4/4) } \\
\text { Other sources (-/2)1991-1993 } \\
\text { From employment (69/33)Sickness allowance (0/4) } \\
\text { Study grant/unemployment benefit (4/3) } \\
\text { Disability pension (3/5) } \\
\text { Other sources (-/2)1994-1996 } \\
\text { From employment (57/28) } \\
\text { Sickness allowance } \\
\text { (2/4)Study grant/ } \\
\text { unemployment benefit (7/5) } \\
\text { Disability pension }(4 / 6) \\
\text { Other sources }(-/ 1) 1997 \\
\text { From employment (58/27)Sickness allowance (2/2) } \\
\text { Study grant/unemployment benefit (6/7) } \\
\text { Disability pension }(2 / 6) \\
\text { Other sources }(-/ 1)\end{array}$ & $\begin{array}{l}\text { After a newly diagnosed unprovoked } \\
\text { epileptic seizure, no negative outcomes } \\
\text { regarding employment and education. } \\
\text { Income increases unless there is an onset of } \\
\text { refractory seizures.Income is lower among } \\
\text { patients with epilepsy than controls. This } \\
\text { difference can be related to overall morbidity. }\end{array}$ \\
\hline
\end{tabular}


Table 3 Summary of findings - indirect costs (Continued)

Balabanov et al.

2007 [24]

Strzelczyk et al.

2013 [23]

Lagunju et al.

2011 [32]

$\begin{array}{ll}\text { Lv et al. } 2009 & \text { Parents of children with epilepsy: } \\ \text { [28] } & \text { Full-time work: (203/263) } \\ & \text { Part-time work: (38/263) } \\ & \text { Don't work for epilepsy: (22/263) } \\ & \text { Parents of children without epilepsy: } \\ & \text { Full-time work: (270/270) }\end{array}$
Days off work, sick leave days

and reduction of salary due to

incapacitation were calculated

for each patient. These costs

were not reported.

\section{(2003 cohort)}

Early retirement: $€ 780$ Productivity

loss due to part-time work/

unemployment: €420Off-days

due to seizures:

$€ 410$ Total indirect costs: $€ 1610$

(2008 cohort)

Early retirement: $€ 818$ Productivity

loss due to part-time work/

unemployment: €441Off-

days due to seizures:

$€ 430$ Total indirect costs: $€ 1689$

Median cost of mother out

of work for one year: US\$ 1280

Abbreviations: $E C$ epilepsy centre, GP general practices, $U H$ university hospital

Parents of children with epilepsy:

Median household

income, Yuan/month: 2800

Mean cost of epilepsy, Yuan/month:4164

Parents of children without epilepsy:

Median household income, Yuan/month:3000
Not reported

The amount and distribution of indirect cost components did not change significantly between cohorts.

Thirty-seven (17.2\%) of mothers gave up their jobs to take care of their child with epilepsy. The annual income lost by families epilepsy. The annual income lost by families
due to this ranged from US\$480 to US\$1280. The overall mean cost of loss of employment across all 215 child participants was US\$493.

Indirect costs of childhood epilepsy have a severe impact on parental quality of life (QoL) and psychological health. Unemployment in particular, can lead

to extreme economic hardship. 
estimated indirect costs (Table 3). The studies were conducted in 16 different countries; seven (from India, and Ecuador, Bulgaria, Nigeria, China, Cameroon and Cote d'Ivoire) were from low or middle income countries.

\section{Direct costs - health system}

The annual total cost per patient in Italy was $€ 1302$ ( $€$ $0.75=\$$ US 1) [14]. A cost-of-illness study from Spain estimated that the total direct costs per patient for the care of a person with epilepsy was of $€ 1055$ per 6 months and the cost of patients attending consultations for epileptic surgery was €2193 [22]. The direct medical costs in France for the first year after newly diagnosed epilepsy were FF14,305 (FF6 = \$US1 in 1998) and FF3,766 during second year [20]. One study from the Netherlands [17] and one study from Italy [16] which focused on children and adolescents compared the direct costs among three different health care settings - general practices, university hospitals and an epilepsy centre. They both found that the costs differ significantly between the different settings of health care, even for patients in the same category of epilepsy.

\section{Determinants of costs and variation in direct costs}

Nine of the eighteen studies that reported direct costs compared different items of expenditures and found that drugs and hospital services were the major sources of costs $[14-17,19,23,24,27,32]$. Three studies from Italy reported that the costs of epilepsy varied significantly depending on the severity of the disease and the response to treatment $[14,16,19]$. Two of them found the annual costs of epilepsy were highest in surgical candidates, followed by patients with drug-resistant epilepsy, active non-drug epilepsy, newly diagnosed epilepsy and epilepsy in remission or with occasional seizures $[14,19]$ A Russian study showed that yearly costs for different types of seizures significantly varied for employed and unemployed participants [27]. After therapy had been optimized using new antiepileptic drugs, four (primary generalized, secondary generalized, partial focal and complex focal) out of five types of seizures, with the exception of polymorphic or undifferentiated seizures were of lower mean cost per year to unemployed patients [27]. In France, the first year costs after newly diagnosed seizures were highly associated with aetiological categorisation of seizures at inclusion and to other clinical parameters such as the number of seizures, age and pattern of seizures or being treated or not by antiepileptic drugs [20]. The costs during the second year had lower variance and were highly related to frequency of seizures and whether the patients were treated with antiepileptic drugs. The highest costs were incurred during the first year after a newly diagnosed seizure.

Two studies found the health care setting was a significant determinant in the variation of direct costs $[16,17]$. For instance in the Netherlands, care provided in a general practice setting cost $€ 52$ per person per month, whilst in a university hospital it cost $€ 282$ and at a specialised epilepsy centre, €357 [17]. These results reflect the varying degrees of severity of epilepsy between the patients treated across the three sites with patients with severe and complex epilepsy most likely treated in the specialised epilepsy centre.

\section{Direct costs - out-of-pocket costs}

As previously reported, six studies from the Netherlands, US, Nigeria, Cameroon, Cote d'Ivoire and India reported out-of-pocket costs. A study from the US [34] and the previously mentioned Dutch study [17] were the only studies that investigated out-of-pocket expenditures in high income countries. In the Netherlands, individuals cared for in a university hospital had the greatest out-ofpocket costs per month $(€ 147)$ followed by patients cared for in a specialised epilepsy centre (€97) and then general practice $(€ 7)$.

In the US, out-of-pocket costs for outpatient visits, hospitals stays, emergency department visits and prescription medications were compared between individuals with epilepsy who were uninsured, had Medicaid coverage, had Medicare ( $<65$ and $\geq 65$ ) or private insurance. The uninsured reported the highest out-of-pocket expenditure US \$ 1018 for hospital stays. Uninsured individuals also experienced significantly higher per-visit and total costs for emergency department care compared with patients in all other insurance groups. They also paid the most out-of-pocket for prescription medication [34].

In Nigeria and Cote d'Ivoire patients with epilepsy were found to incur substantial out of pocket burdens for instance, in Nigeria, $50 \%$ of a cohort of children attending a tertiary centre incurred out of pocket costs of over $20 \%$ annual family income [31, 32]. The high costs of drugs relative to income can also result in nonadherence to medication, as observed in Cote d'Ivoire [31]. However, a program to support access to medications was found to be effective in ensuring that the costs of treatment to patients in rural Cameroon were manageable [30]. A study set in India looked specifically at treatment discontinuation and found that it was associated with high out-of-pocket costs, unemployment and low socioeconomic status.

\section{Indirect costs - productivity loss}

Ten studies from nine countries (Germany, Sweden, Spain, China, India, Netherlands, Nigeria, Ecuador and Bulgaria) estimated the indirect costs related to epilepsy. These studies used a variety of ways to identify indirect costs. Three studies measured the costs in monetary units [22, 23, 32]. A Spanish study provided an average annual cost estimate at $€ 1528$ for lost production [22]. This was measured on the basis of lost employment to patients and caregivers. A 
German study also measured on the basis of lost employment to patients, estimating the total cost of lost production to be $€ 1610$ over a 3 month period [23]. Finally, a study in the Netherlands showed that the loss of productivity due to illness and found that loss of productivity was greatest for patients cared in a specialised epilepsy centre ( 0.26 days per month) and there was no loss of productive days for those cared for in a university hospital and general practice [17].

\section{Indirect costs - employment status}

Five of the studies evaluated the employment circumstances of patients with epilepsy [17, 21, 23, 31, 33] and two studies evaluated the circumstances of parents of children with epilepsy, including work capacity, source of income and incapacity rates [28, 32]. A study from Sweden focused on the incapacity rate and the source of income of patients with epilepsy compared to a control group and found that after a newly diagnosed unprovoked epileptic seizure, no negative impact in terms of employment status. However it found that income was lower in patients with epilepsy than in controls [21].

\section{Determinants of costs and variation in indirect costs}

The Spanish study found that the costs varied significantly between different patients [22] $46 \%$ of the patients had no indirect costs at all whereas $30 \%$ of the patients faced costs of between $€ 3001$ and $€ 4000$ due to loss of employment.

The Dutch study found that patients from an epilepsy centre reported the highest productivity changes and unemployment rates compared with patients from the university hospital and from the general practices [17].

A German study found that the unemployment rate due to epilepsy was higher for non-surgically treated patients with drug-resistant temporal lobe epilepsy compared to surgically treated patients. Freedom from seizures was found to be a significant determinant for socioeconomic outcomes - $64 \%$ of the surgical patients became seizurefree whereas $23 \%$ of the non-surgically treated group achieved freedom from seizures due to modifications in antiepileptic drug treatment [33].

\section{Outcome measurement}

Seven studies assessed direct costs through questionnaires, $[14,16,17,23,24,32]$ five obtained data from medical records $[15,18,27,30,31]$ and five studies used an ad hoc diary to detail information regarding epilepsy care (laboratory and diagnostic tests, outpatient evaluations, hospital admissions) $[16,17,19,23,24]$ Three studies used a hospital database to analyse the use of the various health-care services [22, 27, 29]. Two studies obtained data from a survey which conducted in-person interviews using standard case report forms [20,34] and one from a semi-structured interview [19].

The method of ascertainment was similar amongst the ten studies estimating indirect costs. All of them measured their outcome using self-reported data. Seven studies used a questionnaire [17, 21-23, 26, 28, 32], three used a seizure and cost diary [23-25], and one conducted a semi-structured psychosocial interview [21]. One of the studies also collected information on indirect costs from a social insurance database [21].

\section{Quality of studies}

Overall there was a low risk of bias in the studies reviewed (Table 4). The inclusion criteria were clearly defined for over $90 \%$ of studies. Confounders were only accounted for in $50 \%$ of studies so this may have resulted in an over-

Table 4 Summary of study quality

\begin{tabular}{|c|c|c|c|c|c|c|}
\hline & 1 & 2 & 3 & 4 & 5 & 6 \\
\hline Beghi et al. 2004 [14] & Y & Y & Y & Y & $?$ & Y \\
\hline De Zelicourt et al. 2000 [20] & Y & Y & Y & Y & $?$ & Y \\
\hline Helmstaedter et al. 2000 [33] & Y & Y & N & $?$ & $?$ & Y \\
\hline Lindsten et al. 2002 [21] & Y & Y & N & Y & N & $?$ \\
\hline Pato Pato et al. 2010 [22] & Y & $\mathrm{N}$ & Y & $?$ & Y & Y \\
\hline Das et al. 2007 [25] & Y & Y & N & Y & $?$ & Y \\
\hline Tetto et al. 2002 [19] & Y & $\mathrm{N}$ & Y & $?$ & $?$ & Y \\
\hline Kotsopolous et al. 2003 [17] & Y & $?$ & N & $?$ & $?$ & Y \\
\hline Langfitt et al. 2007 [18] & Y & Y & Y & Y & Y & Y \\
\hline Halpern et al. 2011 [34] & $?$ & Y & N & $\mathrm{N}$ & N & Y \\
\hline Farmer et al. 1992 [26] & Y & $?$ & N & Y & N & $?$ \\
\hline Boon et al 2002 [15] & Y & Y & Y & $?$ & Y & $?$ \\
\hline Guerrini et al. 2001 [16] & Y & Y & $?$ & $?$ & $?$ & $?$ \\
\hline Cockerell et al 1994 [4] & Y & $?$ & $?$ & $\mathrm{~N}$ & $?$ & $?$ \\
\hline Balabanov et al 2008 [24] & Y & Y & N & $?$ & Y & $\mathrm{N}$ \\
\hline Lagunju et al 2011 [32] & Y & Y & Y & N/A & Y & Y \\
\hline Strzelczyk et al 2013 [23] & Y & Y & Y & $?$ & Y & Y \\
\hline Lv et al 2009 [28] & Y & Y & $?$ & $?$ & $?$ & $?$ \\
\hline Doumbia-Outtara et al. 2010 [31] & Y & N/A & Y & $?$ & Y & $\mathrm{N} / \mathrm{A}$ \\
\hline Dongmo et al. 2003 [30] & Y & N/A & Y & $?$ & Y & N/A \\
\hline Haroon et al. 2012 [29] & Y & Y & Y & $?$ & $Y$ & $Y$ \\
\hline Vlasov et al 2010 [27] & Y & $\mathrm{N}$ & ? & $\mathrm{N}$ & Y & Y \\
\hline
\end{tabular}

Measurement of study quality was based on the Joanna Briggs Quality Assessment Appraisal checklist available at:

http://joannabriggs.org/assets/docs/sumari/ReviewersManual-2011.pdf; 2013 Quality appraisal criteria:

1. Were the criteria for inclusion in the sample clearly defined?

2. Were confounding factors identified and strategies to deal with them stated?

3. Were outcomes assessed using objective criteria?

4. Were the outcomes of people who withdrew described and included in the analysis?

5 . Were outcomes measured in a reliable way?

6. Were appropriate statistical analyses used? 
estimation of the effects reported in the other studies. For the most part, outcomes were assessed using objective criteria and measured in a reliable way indicating a low risk of detection bias in the studies reviewed. Attrition bias may be an issue as 15 of the studies did not report outcome data for participants lost to follow-up. Finally, while appropriate statistical analyses were used in most studies, it is worth noting that the analyses were generally limited to descriptive and univariate analyses.

\section{Discussion}

Most studies of the economic impact of epilepsy have focused primarily on the direct costs of treatment and have been conducted in high income country settings. In the small number of studies where patients were followed up from initial diagnosis, such costs were found to peak in the initial year of diagnosis, due mainly to surgery or vagus nerve stimulation (VNS). All studies generally reported significant ongoing costs incurred from medications and outpatient medical consultations, with substantially higher costs associated with ongoing seizures.

Out-of-pocket costs were assessed in six studies. One study from the Netherlands assessed out-of-pocket alongside total costs of treatment and found a significantly large component of direct costs (13\% of costs for patients managed by GPs; $52 \%$ managed though a university hospital; $27 \%$ for epilepsy centre) based mainly on the costs of unpaid care and transportation [17]. This finding suggests that much of the direct costs of treatment and ongoing management for patients with epilepsy may slip through the safety net of existing social health insurance schemes. Thus further research in other settings, including those where ostensible universal coverage arrangements are in place, needs to be undertaken to explore the burden of out-ofpocket costs. Such evidence will most likely be specific to health systems and arrangements within them for the reimbursement of health care costs associated with epilepsy.

In Cote d'Ivoire such costs were found to be a major contributor to non-adherence to medications [31]. In such resource-poor settings, where the availability of safety nets in terms of social health insurance and social welfare are limited or non-existent, the potential economic burden on households is likely to manifest in financial catastrophe, under-treatment, poor adherence and treatment abandonment. Other factors beyond costs also come into play, such as the lack of availability of drugs, stigma associated with epilepsy and negative attitudes towards western medicine.

One study that examined the role of private health insurance from the US found that lack of health insurance coverage was associated with fewer visits to neurologists and greater out-of-pockets costs of medicines, compared to those with insurance. Medicaid coverage was found to offer financial protection in terms of lower out-of-pocket payments despite the same health care utilisation as those with private insurance [34].

Where assessed, indirect costs associated with loss of productivity and employment, were shown to have been major sources of burden associated with this condition. These were reflected in reduced employment/productivity, school attendance and income; as very few of these studies provided monetary estimates of these effects, it is not possible to draw conclusions about the relative burden of indirect from direct costs. The conclusions within individual studies were that indirect costs were overwhelming and constituted a significant burden to individuals and societies, and tended to be greater when there were ongoing seizures particularly among those in lower socioeconomic groups. More data are required to confirm the robustness of these findings in other settings.

We recognise that as the majority of the studies relied exclusively on self-reported costs, there is the potential for recall bias to affect the findings. While prospective diaries may mitigate some of the problems associated with self-report by reducing reliance on patient recall, these are often unreliable when patients lack information about the nature of procedures and tests being carried out. Ideally, future research would involve the use of linked administrative data sets for the assessment of direct health care costs. However, where self-reported is likely to be the only feasible means of collecting data on out-of-pocket and indirect costs, the use of prospective diaries and minimising the time between follow-up interviews may improve the reliability of such data.

Nineteen of the twenty-two studies we identified were cohort studies; the others were a case-control and quasiexperimental studies. The length of follow-up in these studies ranged from 3 months to 6 years; most were 12 to 24 months. Whilst the evidence suggests that long-term direct costs of treatment tends to remain steady (at least for those with control over recurrent seizures), data from patients with longer follow-up will provide a better understanding of treatment compliance and its relationship with costs over time.

A major limitation of this review is the poor comparability of findings across studies due to differences in methods and scope. This limited our ability to make direct comparisons of the size of the burden of epilepsy across different populations and health care settings. On the other hand, the merits of such an exercise may be questionable as it may be more relevant to examine the factors associated with variations in cost, such as insurance coverage and category of illness, as a means of providing guidance for policy and the development and targeting of interventions. It was not possible to provide conclusive assessment of risk of bias due to variation in study questions and study designs. Given that the studies included in this 
review were largely observational and the objective was not to generate an estimate of a pooled treatment effect, such concerns over potential bias can to a large extent be discounted.

A further limitation of this review is that the majority of epilepsy sufferers are found in low and middle income countries in Africa, Central and South America (>80 \%) however most of the published research on this topic and so included in this review have been conducted in higher income countries where epilepsy may be a comparably lower burden. It is likely that this review underestimates the true economic burden faced by households in settings where there are fewer resources and a weaker health system capacity to support people with epilepsy and their households. This misalignment between the regions with the greatest disease burden and populations most researched highlights an urgent need for more research in low and middle income countries to guide policy and planning initiatives to address the economic burden of epilepsy in these settings.

\section{Conclusions}

Our review uncovered a small number of varied studies that have examined the costs associated with treatment of epilepsy. The focus of most of the papers was on the direct costs to health systems but a small number also addressed out-of-pocket and indirect costs associated with loss of income and employment. The main findings are that the key drivers of cost are costs of surgery/VNS, and severity and degree of seizure control. In the Netherlands, where patients are ostensibly protected by universal health care programs, significant out-of-pocket costs were evident due to unpaid care and patient transportation. While in the US, health insurance may offset the costs of treatment and enabling access but does not liberate individuals from bearing a significant burden of out-of-pocket costs associated with ongoing costs of managing illness. Given that the magnitude of such costs is inherently context-specific, there is considerable scope for future research in this aspect of epilepsy, particularly in low and middle income countries.

\section{Additional files}

As an appendix, we have provided the search strategy used to obtained the results of this systematic review. As additional files, we have included completed widely accepted systematic review guidelines: the Preferred Reporting Items for Systematic Reviews and MetaAnalyses (PRISMA) and Guidelines for Meta-Analyses and Systematic Reviews of Observational Studies (MOOSE). In addition, we have provided the data extraction form employed by the authors to undertake data extraction for each included paper.

\section{Appendix}

\section{Search Strategy}

Stage 1:

1. exp Epilepsy/

2. epileptic\$.mp.

3. seizure\$.mp. or exp Seizures/

4. or $/ 1-3$

5. DEPRESSION/or DEPRESSION, INVOLUTIONAL/

6. mental disorders/or adjustment disorders/or exp anxiety disorders/or dissociative disorders/ or exp mood disorders/or neurotic disorders/

7. crying/or laughter/or affective symptoms/or exp emotions/or depression/

8. behavioral symptoms/or exp aggression/or motivation/or drive/or behavior/or fatigue/or exp suicide/or anxiety/

9. (tearful\$ or apprehens\$ or uneas\$ or mania or laugh\$ or cry\$ or suicid\$ or dysthymi\$ or panic or fear or apathy or anger or aggressi\$).mp.

10. nonverbal communication/

11. ((mental or psychiatric or negative or bipolar or dysthymic) adj symptom\$).mp.

12. ((mental or affective or bipolar or dysthymic or sleep) adj disorder\$).mp.

13. (emotion $\$$ or depress $\$$ or anxiety or fatigue or mood or irritability or worry or tension or distress\$ or neuroses or dysthymi\$).mp.

14. Cognition Disorders/or cognit\$ disord\$.mp. [mp = title, abstract, original title, name of substance word, subject heading word, protocol supplementary concept, rare disease supplementary concept, unique identifier]

15. or/5-14

16. exp Employment/

17. employ\$.mp.

18. exp Work/

19. vocation\$.mp.

20. perform $\$ . m p$.

21. occupation\$.mp.

22. exp School/

23. academi\$.mp.

24. university\$.mp.

25. stud\$.mp.

26. or/16-25

27. exp economics/

28. exp income/

29. exp health care costs/

30. cost of illness/

31. exp economics medical/

32. exp economics hospital/

33. economics pharmaceutical/

34. expen\$.mp. 
35. or/27-34

36. social\$.mp.

37. friends/or family/or peers/or isolat $\$$ /or interperson\$/or support/

38. stigma\$.mp.

39. discrimin\$.mp. or exp discrimination/

40. or/36-39

41. "Quality of life"/

42. "Value of life"/

43. Quality-adjusted life years/

44. (qaly\$ or qald\$ or qale\$).mp.

45. daly\$.mp.

46. health status indicators/

47. (satisfact\$ or well\$ or activ\$ or physical\$ or energ\$ or life $\$$ or role\$ or vital\$).mp.

48. or/41-47

49. 4 and 15 and 26 and 35 and 40 and 48

Stage 2:

1. exp Epilepsy/

2. epileptic\$.mp.

3. seizure\$.mp. or exp Seizures/

4. or/1-3

5. exp economics/

6. exp income/

7. exp health care costs/

8. cost of illness/

9. exp economics medical/

10. exp economics hospital/

11. economics pharmaceutical/

12. expen\$.mp.

13. or $/ 5-12$

14.4 and 13

\section{Additional files}

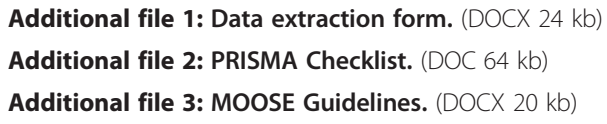

Additional file 1: Data extraction form. (DOCX $24 \mathrm{~kb}$ )

Additional file 2: PRISMA Checklist. (DOC 64 kb)

Additional file 3: MOOSE Guidelines. (DOCX 20 kb)

\section{Abbreviations}

NHMRC: National Health and Medical Research Council; ARC: Australian Research Council; ILAE: International League Against Epilepsy; VNS: Vagus nerve stimulation.

\section{Competing interests}

None of the authors have any conflict of interest to disclose.

\section{Authors' contributions}

$\mathrm{BE}, \mathrm{MLH}, \mathrm{CSA}$ and $\mathrm{SJ}$ conceived of the study and participated in its design and coordination. KP and MLH developed the search strategy. KP, MLH and $J M$ identified and reviewed papers for inclusion. KA, FS, MLH and JM assessed risk of bias. KA, BE, MLH, CSA and SJ helped to draft the manuscript. All authors read and approved the final manuscript.

\section{Acknowledgements}

The authors would like to thank Dr. Mansur Kutlubaev for his assistance in translating the Russian study reviewed.

This study is funded by a National Health and Medical Research Council (NHMRC) of Australia Partnership Grant 571448 and an Australian Research Council (ARC) Discovery Grant DP1096655. During the conduct of this project, BE received an lan Potter Foundation Fellowship, MLH held National Heart Foundation Future Leader Fellowship 100034. CSA holds an NHMRC Senior Principal Research Fellowship and SJ holds an NHMRC Senior Research Fellowship.

The funders had no role in the conduct or reporting of this study.

\section{Author details}

${ }^{1}$ The George Institute for Global Health, University of Sydney, Level 10, King George V Building, 83-117 Missenden Rd, PO Box M201, Camperdown, NSW 2050, Australia. ${ }^{2}$ University of Bremen, Bibliothekstraße 1, 28359 Bremen, Germany. ${ }^{3}$ The Menzies Centre for Health Policy, University of Sydney, D02 Victor Coppleson Building, Sydney, NSW 2006, Australia. ${ }^{4}$ Royal Prince Alfred Hospital, Level 11, KGV Building, Missenden Road, Camperdown, NSW 2050, Australia.

Received: 6 August 2015 Accepted: 13 November 2015

Published online: 25 November 2015

\section{References}

1. Kotsopoulos IA, Van Merode T, Kessels FG, De Krom MC, Knottnerus JA. Systematic Review and Meta-analysis of Incidence Studies of Epilepsy and Unprovoked Seizures. Epilepsia. 2002;43(11):1402-9.

2. Sander J, Shorvon S. Incidence and prevalence studies in epilepsy and their methodological problems: a review. J Neurol Neurosurg Psychiatry. 1987; 50(7):829-39.

3. Forsgren I, Beghi E, Ekman M. Cost of epilepsy in Europe. Eur J Neurol. 2005; 12(s1):54-8.

4. Cockerell OC, Hart YM, Sander JW, Shorvon SD. The cost of epilepsy in the United Kingdom: an estimation based on the results of two population-based studies. Epilepsy Res. 1994;18(3):249-60.

5. Hackett ML, Glozier NS, Martiniuk AL, Jan S, Anderson CS. Sydney epilepsy incidence study to measure illness consequences: the SESIMIC observational epilepsy study protocol. BMC Neurol. 2011;11(1):3.

6. Strzelczyk A, Reese JP, Dodel R, Hamer HM . Cost of epilepsy: a systematic review. Pharmacoeconomics. 2008;26(6):463-76.

7. Pugliatti M, Beghi E, Forsgren L, Ekman M, Sobocki P. Estimating the cost of epilepsy in Europe: a review with economic modeling. Epilepsia. 2007; 48(12):2224-33.

8. Beghi E, Frigeni B, Beghi M, De Compadri P, Garattini L. A review of the costs of managing childhood epilepsy. PharmacoEconomics. 2005;23(1):27-45.

9. Begley CE, Beghi E. The economic cost of epilepsy: a review of the literature. Epilepsia. 2002;43(s4):3-9.

10. Brunetti M, Pagano E, Garattini L. The economic cost of epilepsy: a review. Ital J Neurol Sci. 1998;19(2):116-9.

11. Ekman M, Forsgren L. Economic evidence in epilepsy: a review. Eur J Health Econ. 2004;5:s36-42.

12. Fisher RS, Boas WE, Blume W, Elger C, Genton P, Lee P, et al. Epileptic seizures and epilepsy: definitions proposed by the International League Against Epilepsy (ILAE) and the International Bureau for Epilepsy (IBE). Epilepsia. 2005;46(4):470-2.

13. The Joanna Briggs Institute. Joanna Briggs Institute Reviewers' Manual: 2011 Edition. Appendix VII - MAStARI critical appraisal tools. 2011. http:// joannabriggs.org/assets/docs/sumari/ReviewersManual-2011.pdf. Accessed 22 December 2014.

14. Beghi E, Garattini L, Ricci E, Cornago D, Parazzini F. Direct Cost of Medical Management of Epilepsy among Adults in Italy: A Prospective Cost-of-Illness Study (EPICOS). Epilepsia. 2004;45(2):171-8.

15. Boon P, D'Have M, Van Walleghem P, Michielsen G, Vonck K, Caemaert J, et al. Direct medical costs of refractory epilepsy incurred by three different treatment modalities: A prospective assessment. Epilepsia. 2002; 43(1):96-102.

16. Guerrini R, Battini R, Ferrari A, Veggiotti P, Besana D, Gobbi G, et al. The costs of childhood epilepsy in Italy: comparative findings from three health care settings. Epilepsia. 2001;42(5):641-6. 
17. Kotsopoulos IA, Evers SM, Ament AJ, Kessels FG, de Krom MC, Twellaar M, et al. The costs of epilepsy in three different populations of patients with epilepsy. Epilepsy Res. 2003;54(2):131-40.

18. Langfitt J, Holloway R, McDermott M, Messing S, Sarosky K, Berg A, et al. Health care costs decline after successful epilepsy surgery. Neurology. 2007; 68(16):1290-8.

19. Tetto A, Manzoni P, Millul A, Beghi E, Garattini L, Tartara A, et al. The costs of epilepsy in Italy: A prospective cost-of-illness study in referral patients with disease of different severity. Epilepsy Res. 2002:48(3):207-16.

20. De Zelicourt M, Buteau L, Fagnani F, Jallon P. The contributing factors to medical cost of epilepsy: An estimation based on a French prospective cohort study of patients with newly diagnosed epileptic seizures (the CAROLE study). Seizure. 2000;9(2):88-95.

21. Lindsten $H$, Stenlund $H$, Edlund C, Forsgren L. Socioeconomic Prognosis after a Newly Diagnosed Unprovoked Epileptic Seizure in Adults: A Population-based Case-Control Study. Epilepsia. 2002;43(10):1239-50.

22. Pato Pato A, Cebrian Perez E, Cimas Hernando I, Lorenzo Gonzalez JR, Rodriguez Constenla I, Gude SF. Analysis of direct, indirect, and intangible costs of epilepsy. Neurologia. 2011;26(1):32-8.

23. Strzelczyk A, Haag A, Reese JP, Nickolay T, Oertel WH, Dodel R, et al. Trends in resource utilization and prescription of anticonvulsants for patients with active epilepsy in Germany. Epilepsy Behav. 2013;27(3):433-8.

24. Balabanov PP, Zahariev ZI, Mateva NG. Evaluation of the factors affecting the quality of life and total costs in epilepsy patients on monotherapy with carbamazepine and valproate. Folia Med. 2007;50(2):18-23.

25. Das K, Banerjee M, Mondal G, Devi LG, Singh O, Mukherjee B. Evaluation of socio-economic factors causing discontinuation of epilepsy treatment resulting in seizure recurrence: a study in an urban epilepsy clinic in India. Seizure. 2007; 16(7):601-7.

26. Farmer P, Placencia M, Jumbo L, Sander J, Shorvon S. Effects of epilepsy on daily functioning in northern Ecuador: summary of findings of a populationbased research project. Neuroepidemiology. 1992;11(4-6):180-9.

27. Vlasov PN, Orekhova NV. The cost-benefit analysis of new antiepileptic drugs. Zhurnal Nevrologii I Psihiatrii imeni S.S. Korsakova. 2010;111(10):39-43.

28. Lv R, Wu L, Jin L, Lu Q, Wang M, Qu Y, et al. Depression, anxiety and quality of life in parents of children with epilepsy. Acta Neurol Scand. 2009;120(5): 335-41.

29. Haroon A, Tripathi M, Khanam R, Vohora D. Antiepileptic drugs prescription utilization behaviour and direct costs of treatment in a national hospital of India. Ann Indian Acad Neurol. 2012;15(4):289.

30. Dongmo L, Echouffo B, Njamnshi A, Kamdem P, Sini V, Pepouomi M. Difficulties faced in the management of epilepsy in rural Cameroon: the case of Mbangassina locality. Afr J Neurol Sci. 2003;22(1).

31. Doumbia-Ouattara M, Yapo F, Kouassi L, Kouame-assouan AE, Aka-Diarra E, Sonan-Douayoua T. Evaluation of the treatment of adults epileptic inpatients in the Department of Neurology at Teaching Hospital of Yopougon Abidjan-Cote d'I'voire. Afr J Neurol Sci. 2010;29(1).

32. Lagunju I, Imam Z, Adedokun B. Cost of epilepsy in children attending a tertiary centre in Nigeria. International Health. 2011;3(3):213-8.

33 Helmstaedter C, Kurthen M, Lux S, Johanson K, Quiske A, Schramm J, et al. Temporal lobe epilepsy: longitudinal clinical, neuropsychological and psychosocial follow-up of surgically and conservatively managed patients. Nervenarzt. 2000;71(8):629-42

34 Halpern MT, Renaud JM, Vickrey BG. Impact of insurance status on access to care and out-of-pocket costs for US individuals with epilepsy. Epilepsy Behav. 2011;22(3):483-9.

\section{Submit your next manuscript to BioMed Central and we will help you at every step:}

- We accept pre-submission inquiries

- Our selector tool helps you to find the most relevant journal

- We provide round the clock customer support

- Convenient online submission

- Thorough peer review

- Inclusion in PubMed and all major indexing services

- Maximum visibility for your research

Submit your manuscript at www.biomedcentral.com/submit
() Biomed Central 